3. Bùi Thị Ngà và cộng sự (2012), "Đánh giá chất lương chăm sóc ngưới bệnh toàn diên của người điểu dưỡng bênh viện Ỳ học Cổ truyền Trung ương", Tạp chí nghiên cứu Y dược học cổ truyền Viêt Nam, số 33, tr 58-63.

4. Nguyê̂n Trường Sơn (2010), "Tìm hiểu cảm xúc và nhu câu chăm sóc về mặt tinh thân của người bênh ở bênh viên trường đại học $Y$-Dược Huế" ${ }^{\prime \prime}$ Kỷ yểu đề tài nghiên cứu khoa học điêu dưỡng Hội nghi khoahoc điều dưỡng toàn quốc lần thứ IV, tr $208-216$.

5. Trân Ngọc Trung (2012), Đánh giá hoạt động chăm sóc người bệnh của điều dưỡng tại khối Nội và khối Ngoại Bệnh viện Đa khoa tỉnh Lâm Đồng, năm 2012, Luận văn thạc sỹ quản lý bệnh viện, Trường Đai hoc Y tế Công cônng, Hà Nối.

6. Baum et ai (2013), The potential for multidisciplinary primary health care services to take action on the social determinants of health: actions and constraints, BMC Public Health: 13:460.

7. Happell Brenda, Platania-Phung Chris, Scott David (2013), Physical health care for people with mental illness: Training needs for nurses, Nurse Education Today, 33, pp. 396-401

\title{
THỰC TRẠNG HộI CHỨNG SẢNG Ở NGƯỜI TỪ 60 TUỔI TRỞ LÊN TẠI KHOA CẨP CỨU BỆNH VIÊ̂N LÃO KHOA TRUNG ƯƠNG
}

\section{TÓM TẮT}

Chúng tôi thực hiện nghiên cứu với mục tiêu mô tả thực trang hội chứng sảng ở người bênh từ 60 tuổi trở lên tại Khoa cấp cứu bệnh viện Lão khoa Trung ương. Đây là một nghiên cứu mô tả cắt ngang, thực hiện trên 106 bệnh nhân từ 60 tuổi trở lển đến khám và điều trị tại Khoa cấp cứu bệnh viện Lão khoa Trung ương và được chẩn đoán hội chứng sảng theo tiêu chuẩn chẩn đoán của ICD 10. Kết quả: Người bênh có hội chứng sảng thường gặp là nhóm tuổi $80-89$, tuổi trung bình là $78,3 \pm 10,9$, nam giới gặp nhiều hớn nữ giới $(52,8 \%$ và $47,2 \%)$. Phần lớn bệnh nhân đang sống cùng gia đình $(68,9 \%)$, chỉ có 2 trường hợp sống trong nhà dưỡng lão $(1,9 \%)$. Đa số người bệnh có biểu hiện suy giảm thị giác $(87,7 \%)$ và suy giảm thính giác $(81,1 \%)$. Triệu chứng gặp nhiều nhất là biểu hiện rối loạn định hướng không gian và giảm trí nhớ gần với tỉ lệ là $89,6 \%$. Tiếp đó đến biểu hiện giảm khả năng duy trì sự chú ý $(61,3 \%)$. Ít gặp nhất là biểu hiên đảo ngước chu kì thức ngủ (24,5\%).

Từ khoá: hội chứng sảng; người già.

\section{SUMMARY}

SITUATION OF DELIRIUM SYNDROME AMONG PATIENTS AGED 60 YEARS AND OLDER IN EMERGENCY DEPARTMENT IN NATIONAL GERIATRIC HOSPITAL

Our study aimed to describe the situation of delirium syndrome among patients aged 60 years and older in Emergency Department in National Geriatric Hospital. This is a cross-sectional descriptive study, including 106 patients aged 60 years and older who came for examination and treatment in Emergency

\footnotetext{
${ }^{1}$ Đai hoc Y Hà Nôi

2 Viện Sức Khỏe Tâm Thần - Bênh Viên Bach Mai

Chịu trách nhiệm chính: Trần Nguyễn Ngọc

Email: trannguyenngoc@hmu.edu.vn

Ngày nhận bài: 10.9.2021

Ngày phản biên khoa hoc: 2.11.2021

Ngày duyệt bài: 12.11.2021
}

\begin{abstract}
Dương Minh Tâm ${ }^{1,2}$, Trần Nguyễn Ngọc ${ }^{1,2}$
Department in National Geriatric Hospital, were diagnosed with delirium syndrome according to diagnostic criteria of ICD 10. Results: Most of patients had delirium symptoms were in the age group of $80-$ 89 years old, the mean age was $78.3 \pm 10.9$. There was a small gender difference, men were more common than women (52.8\% and $47.2 \%)$. Most elderly people lived with their families $(68.9 \%)$. There were 2 cases livedg in the nursing home (1.9\%). Most of the patients had visual impairment $(87.7 \%)$ and hearing loss $(81.1 \%)$. The most common symptoms were spatial orientation disorder and memory loss, with the same rate of $89.6 \%$, followed by the decrease in attention span (61.3\%). The least common was sleep-wake cycle reversal (24.5\%).

Keywords: delirium syndrome; elderly people.
\end{abstract}

\section{I. ĐĂT VẤN ĐỀ}

Hội chứng sảng là một hội chứng phổ biến ở những người cao tuổi ở nhóm bênh nhân nội trú. Khoa cấp cứu đóng vai trò trung tâm trong một bệnh viện và là cửa ngõ đầu vào cho phần lớn các trường hợp nhập viên. Ước tính có tới 7 20\% bênh nhẩn cao tuổi có hội chứng sảng được nhập vào khoa cấp cứu. ${ }^{1}$ Tuy nhiên, các nghiên cứu cho thấy có tới $30 \%$ đến $67 \%$ người bệnh cao tuổi có hội chứng sảng không được phát hiện trên lâm sàng. ${ }^{2}$ Hiện nay có nhiều cách để chia nhóm người cao tuổi. Người giai đoạn đầu tuổi già từ 60 trở lên hoặc 65 - 74 tuổi, người giai đoann giữa tuổi già từ 70 tuổi trở lên hoăc 75 - 84 tuổi và người giai đoạn cuối tuổi già từ 80 tuổi trở lên hoặc từ 85 tuổi trở lên. Trong nghiên cứu này, chúng tôi muốn nghiên cứu để làm rõ thực trang của hội chứng sảng ở nhóm tuổi từ 60 trở lên tại khoa cấp cứu bênh viên Lão khoa trung ương. Mục tiêu của nghiên cứu là "mô tả thực trạng hội chứng sảng ở người từ 60 trở lên tại khoa cấp cứu bệnh viện Lão khoa trung ương". 
II. ĐỐI TƯỢNG VÀ PHƯƠNG PHÁP NGHIÊN CỨU

2.1. Thiết kế nghiên cứu. Thiết kế được sử dụng là nghiên cứu mô tả cắt ngang.

2.2. Thời gian, đối tượng và địa điểm nghiên cứu

2.2.1. Thời gian nghiên cứu: từ tháng 7/2019 đến tháng 10/2020.

\subsection{2. Đối tượng nghiên cứu}

Nghiên cứu lựa chọn đối tượng tham gia là (i) người đến khám và điều trị tại khoa Cấp cứu bệnh viện Lão khoa Trung ương, (ii) có độ tuổi $\geq$ 60 , (iii) có thông tin đầy đủ về hành chính, tiền sử, bệnh sử, khám lâm sàng, các thông số cận lâm sàng. Nghiên cứu loại những người (i) nghiện chất hoặc lạm dụng chất; (ii) người thân hoặc người chắm sóc không có khả năng hiểu, trả lời trong quá trình thu thập thông tin (iii) (v) người thân hoặc người chăm sóc và bản thân người bệnh không đồng ý tham gia nghiên cứu.

2.2.3. Địa điểm nghiên cứu. Nghiên cứu được tiến hành tại khoa khoa Cấp cứu bệnh viện Lão khoa.

2.3. Cỡ mẫu và cách chơn mẫu. Nghiên cứu sử dụng cách chọn mẫu ngẩu nhiên,

Áp dụng công thức tính cõ̃ mẫu cho một tỷ lệ cho nghiên cứu mô tả lâm sàng:

$$
n=Z_{1-\frac{a}{2}}^{2} \times \frac{p(1-p)}{\Delta^{2}}
$$

Trong đó: n: là cõ̃ mẫu nghiên cứu

$p=56 \%$ là tỷ lệ người bệnh mê sảng theo Tamara G. Fong (2009). ${ }^{3}$

$$
\text { Hệ số tin cậy } Z_{1-\frac{\alpha}{2}}^{2}=1,96^{2}
$$

$\Delta$ : là độ chính xác mong muốn giữa mẫu và quần thể. Ước tính $\Delta=0,08$

Cỡ mẫu tối thiểu là 148 người vào Khoa Cấp cứu bệnh viện Lão khoa Trung ương. Kết thúc nghiên cứu đã thu thập được 163 người đủ tiêu chuẩn lựa chọn và tiêu chuẩn loại trừ. Trong đó có 106 người bệnh có hội chứng sảng.

2.4. Biến số nghiền cứu. Tuối, giới, hoàn cảnh sống, tiền sử bệnh, các triệu chứng của hội chứng sảng.

*Hội chứng sảng được xác định theo tiêu chuẩn chẩn đoán của ICD - 10:

A. Có ý thức u ám, có nghĩa là giảm độ tỉnh táo của sự nhận biết về môi trường xung quanh, giảm khả năng tập trung, duy trì hoặc thay đổi chú ý.

B. Rối loạn nhận thức được biểu hiện bằng cả hai triệu chứng sau:

(1). Tổn thương trí nhớ tức thì và trí nhớ gần, với trí nhớ xa không bị ảnh hưởng.

(2). Rối loạn định hướng về thời gian, không gian hoặc người xung quanh.

C. Ít nhất một trong các rối loạn tâm thần vận động sau xuất hiện:

(1). Sự dao động nhanh và không thể đoán trước từ giảm sang tăng hoạt động

(2). Tăng thời gian phản ứng

(3). Tăng hoăcc giảm dòng ngôn ngữ

(4). Tăng phản ứng giật mình

D. Có rối loạn giấc ngủ hoăc chu kỳ thức ngủ, biểu hiện bằng ít nhất mộ̣t trong các triệu chứng sau:

(1). Mất ngủ, trong những trường hợp trầm trọng có thể mất ngủ hoàn toàn, kèm theo sự ngủ gật ban ngày hoặc không, hoặc đảo ngược chu kỳ thức - ngủ

(2). Sự nặng lên của triệu chứng vào ban đêm.

(3). Các giấc mơ hỗn độn và có ác mộng, có thể tiếp diễn dưới dạng ào giác hoặc ảo tưởng sau khi thức dậy.

E. Các triệu chứng có khởi phát nhanh và biểu hiện dao động trong ngày

F. Có bằng chứng khách quan từ bênh sử, khám cơ thể và thần kinh hoặc xét nghiệm, của một bệnh não hoặc bệnh hệ thống tiềm ẩn (không phải bệnh liên quan đến chất tác động tâm thần) có thể được thừa nhận là nguyên nhân của các biểu hiện lâm sàng trong các tiêu chuẩn từ $A$ đến $D$.

Các rối loạn cảm xúc như trầm cảm, lo âu hoặc lo sợ, khó chịu bứt rứt, khoái cảm, vô cảm hoặc cực kỳ bối rối, rối loạn tri giác (ảo tưởng, ảo giác, thường là thị giác) và các hoang tưởng nhất thời là điển hình nhưng không đặc hiệu đối với chẩn đoán này

2.5. Công cụ thu thập số liệu. Bệnh án nghiên cứu (được thiết kế riêng phù hợp với nghiên cứu).

2.6. Phân tích số liệu. Nhập liệu và xử lý số liệu bằng phần mềm thống kê SPSS 20.0

2.7. Đạo đức nghiên cứu. Đối tượng và người thân tham gia nghiên cứu được giải thích cặn kẽ, cụ thể về mục đích, nội dung cũng như những lợi ích và nguy cơ có thể xảy ra khi tham gia. Đây là nghiên cứu mô tả không can thiệp vào quá trình điều trị.

Các đối tượng tham gia nghiên cứu là hoàn toàn tự nguyện và có quyền rút khỏi nghiên cứu.

Mọi thông tin của đối tượng được đảm bảo giữ bí mật.

\section{KẾT QUẢ NGHIÊN CỨU}

Bảng 3.1: Đặc điểm về tuổi của người bệnh sảng $\geq 60$ tuổi $(n=106)$

\begin{tabular}{|c|c|c|}
\hline Nhóm tuối & SL & \% \\
\hline $60-69$ & 25 & 23,6 \\
\hline
\end{tabular}




\begin{tabular}{|c|c|c|}
\hline $70-79$ & 28 & 26,4 \\
\hline $80-89$ & 36 & $\mathbf{3 4 , 0}$ \\
\hline$\geq 90$ & 17 & 16,0 \\
\hline Tống & 106 & 100,0 \\
\hline$X \pm$ SD & \multicolumn{2}{|c|}{$\mathbf{7 8 , 3} \pm \mathbf{1 0 , 9}$} \\
\hline
\end{tabular}

Nhân xét: Nhóm tuối thường gặp hội chứng sảng là 80 - 89 tuổi, tiếp đó đến nhóm tuổi $70-$ 79 với tỉ lệ $26,4 \%$. Tuổi trung bình mắc hội chứng sảng là 78,3 $\pm 10,9$.

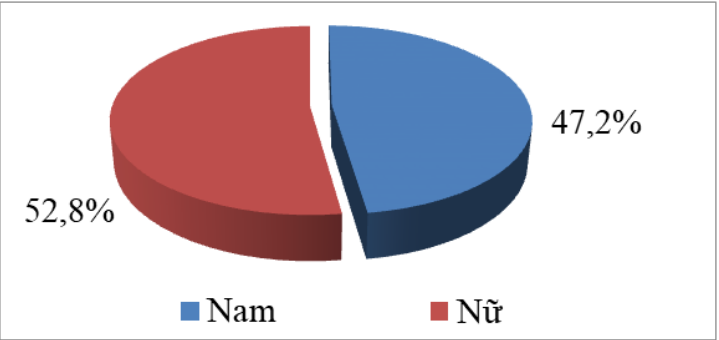

Biểu đồ 3.1: Phân bố theo giới ở người bênh sảng $\geq 60$ tuôii $(n=106)$

Nhân xét: Người bệnh có hội chứng sảng từ 60 tuổi trở lên thường gặp nhất là nam giới. Tỉ lệ nam/nũ̃ xấp xỉ 1/1.

Bảng 3.2. Đặc điểm hoàn cảnh sống ở người bệh sảng $\geq 60$ tuối $(n=106)$

\begin{tabular}{|c|c|c|}
\hline Triệu chứng & $\mathbf{S L}$ & $\mathbf{\%}$ \\
\hline Gia đình (Vợ/chồng/con) & 73 & $\mathbf{6 8 , 9}$ \\
\hline Sống cùng người chăm sóc & 24 & 22,6 \\
\hline Sống một mình & 7 & 6,6 \\
\hline Nhà dưỡng lão & 2 & 1,9 \\
\hline Tống & $\mathbf{1 0 6}$ & $\mathbf{1 0 0 , 0}$ \\
\hline
\end{tabular}

Nhận xét: Phần lớn người bệnh $\geq 60$ tuổi mắc hội chứng sảng đang sống cùng gia đình $(68,9 \%)$. Tiếp đó sống cùng người chăm sóc với tỉ lệ 22,6\%. Có 2 trường hợp sống trong nhà dưỡng lão chiếm tỉ lệ 1,9\%.

Bảng 3.3. Tỉ lệ các triệu chứng trong hội chứng sảng ở người $\geq 60$ tuổi $(n=106)$

\begin{tabular}{|c|c|c|}
\hline Triệu chứng & $\mathbf{S L}$ & $\mathbf{\%}$ \\
\hline Giảm khả năng duy trì sự chú ý & 65 & 61,3 \\
\hline Giảm trí nhớ gần & 95 & $\mathbf{8 9 , 6}$ \\
\hline Rối loạn định hướng không gian & 95 & $\mathbf{8 9 , 6}$ \\
\hline Giảm dòng ngôn ngữ & 45 & 42,5 \\
\hline Đảo ngược chu kì thức ngủ & 26 & 24,5 \\
\hline Tăng phản ứng giật mình & 53 & 50,0 \\
\hline
\end{tabular}

Nhận xét: Trong hội chứng sảng ở người $\geq$ 60 tuối, phần lớn người bệnh có biểu hiện rối loạn định hướng không gian và giảm trí nhớ gần với tỉ lệ tương đương nhau là 89,6\%. Tiếp đó đến biểu hiện giảm khả năng duy trì sự chú ý (61,3\%). Ít gặp nhất là biểu hiện đảo ngược chu kì thức ngủ $(24,5 \%)$.

\section{BÀN LUÂN}

Kết quả ở bảng 3.1 cho thấy người bệnh sảng từ 60 tuổi trở lên thường gặp sảng nhất là 80 89 tuổi $(34,0 \%)$, tiếp đó đến nhóm tuổi $70-79$ với tỉ lệ $26,4 \%$. Tuổi trung bình mắc hội chứng sảng ở độ tuổi từ 60 trở lên là $78,3 \pm 10,9$. Kết quả nghiên cứu này tương đồng với kết quả nghiên cứu của một số tác giả trên thế giới. Kết quả nghiên cứu của Christopher R. Carpenter (2011) cho biết ở nhóm có sảng tuổi trung bình là $77 \pm 8$ tuổi, ở nhóm chung tuổi trung bình là $78 \pm 8$ tuổi ${ }^{4}$ Kết quả nghiên cứu ở biểu đồ 3.1 cho thây, tỉ lệ nữ giới cao hơn tỉ lệ nam giới với $52,8 \%$ và $47,2 \%$. Kết quả nghiên cứu của chúng tôi giống với kết quả nghiên cứu của Jin $\mathrm{H}$. Han (2017). ${ }^{5}$ Bảng 3.2 cho thấy chiếm tỉ lệ cao nhất là những bệnh nhân có hoàn cảnh sống cùng gia đình. Tiếp theo là những bệnh nhân sống cùng người chăm sóc. Ít gặp nhất là nhưng bệnh nhân sống ở nhà dưỡng lão. Điều đặc biệt là trong nghiên cứu ghi nhận có 2 bệnh nhân sảng sống ở nhà dưỡng lão. Kết quả này cũng tương đồng với kết quả của một số tác giả. Trên thực tế số bệnh nhân ở tại viện dưỡng lão ở Việt Nam còn rất ít do hệ thổng y tế công chăm sóc cho người cao tuổi tại Việt Nam còn thiếu sót, vì vậy con số chúng tôi nhận thấy sẽ có sự khác biệt lớn với các nghiên cứu tiến hành tại các quốc gia khác.

Bảng 3.3 cho thấy người bệnh suy giảm thị giác có tỉ lệ cao $(87,7 \%)$. Kết quả nghiên cứu này tương đồng với kết quả nghiên cứu của Margaret A. Pisani (2007) và cộng sự. ${ }^{6}$ Suy giảm thị giác là sự hạn chế chức nắng của mắt hoặc hoặc hệ thống thị lực còn gọi là suy giảm thị giác hoắc mất thị giác. Suy giảm thị giác ở người cao tuổi là một vấn đề sức khỏe lớn. Khi tuổi cao, chức năng bình thường của các mô mắt giảm và tỉ lệ mắc bệnh lý mắt tăng lên. Các nghiên cứu đã chỉ ra rẳng tuổi là yếu tố dự báo tốt nhất về mù lòa và suy giảm thị lực. Suy giảm thị lực có thể tác động nhiều đển chất lượng cuộc sống của bệnh nhân, liên quan đến sự cô lập xã hội, lo lắng, trầm cảm và mất tính độc lập. Có thế ảnh hưởng đến sự cân bằng, dẫn đến ngã thường xuyên hơn và ảnh hưởng tiêu cực đến hoạt động thể chất. Suy giảm thị lực có thể điều trị và phòng bệnh được.

Suy giảm thính giác là giảm hoặc mất dần thính lực xảy ra khi tuổi già. Suy giảm thính lực thường gặp nhất ở tuổi già. Trong số những người trên 60 tuổi, hơn 20\% những người được khảo sát gặp khó khăn với thính giác của họ và ở những người trên 70 tuổi, con số này là hơn $30 \%$. Trong những năm gần đây, sự tương tác giữa suy giảm thính giác với các yếu tố nhận thức được quan tâm nhiều hơn. Trong nghiển 
cứu chúng tôi cũng cố gắng khảo sát tình trạng suy giảm nhận thức ở những bệnh nhân đến khoa cấp cứu bệnh viên Lão khoa Trung ương. Kết quả cho thấy ở nhóm bệnh nhân chung có suy giảm thính giác chiếm tî̉ lệ cao với $81,1 \%$ (bảng 3.3). Tương tự như vậy, Margaret A. Pisani (2007) cho biết trong những bệnh nhân suy giảm thính giác, tỉ lệ bệnh nhân có sảng cũng cao hơn tỉ lệ bệnh nhần không có sảng $(17,3 \%$ và $16,7 \%) .{ }^{6}$ Hút thuốc lá để lại hậu quả bệnh tật lớn cho người cao tuổi. Người hút thuốc lớn tuổi ít có khả năng cố gắng bỏ thuốc hơn những người hút thuốc trẻ tuổi. Tỉ lệ mắc bệnh và tử vong tuyệt đối do hút thuốc lá tăng đều đặn khi tuổi và thời gian hút thuốc ngày càng tăng. Do sự gia tăng đáng kể tỉ lệ tử vong do hút thuốc quá mức theo tuổi tác nển khoảng $70 \%$ trong số 400.000 ca tử vong trở lên xảy ra ở những người trên 60 tuổi. Những lợi ích của việc cai thuốc có phần ít hơn ở người cao tuổi và có thể biểu hiện chậm hơn so với những người trẻ tuổi hút thuốc, nhưng ngừng thuốc vẫn là cách hiệu quả nhất để thay đổi các nguy cơ mắc bệnh do hút thuốc ở mọi lứa tuổi, kể cả những người trên 60 tuổi. Khảo sát tiền sử hút thuốc lá của bệnh nhân, chúng tôi nhận thấy phần lớn người bệnh sảng có tiền sử hút thuốc lá (bảng 3.3). Uống rượu có nguy cơ gây ra một tỉ lệ lớn các tác hại đối với sức khỏe và hạnh phúc của người lớn tuổi. Trong nghiên cứu, khảo sát tiền sử uống rượu chúng tôi nhận thây các bệnh nhân có tỉ lệ uống rượu không cao. Chỉ khoảng 28,3\% (bảng 3.3). Tuy nhiên, kết quả của chúng tôi có khác nhiêu so với kết quả của Margaret $A$. Pisani và cộng sự (2007). ${ }^{6}$ Giải thích cho sự khác nhau về kết quả là do nghiên cứu của chúng tôi tiến hành địa điểm nghiên cứu và cỡ mấu khác nhau. Ngoài ra nữ giới ở Việt Nam ít có thói quen sử dụng rượu và các chất kích thích.

$Y$ thức là một chức năng của não cho phép nhận thức về bản thân và môi trường và được đặc trưng bởi hai khía cạnh chính: mức độ ý thức và nội dung của ý thức. Mức độ ý thức phản ánh tình trạng thức tỉnh và sự cảnh giác: tỉnh táo, ngủ sâu hoặc hôn mê. Nội dung của ý thức là sự nhận thức về bản thần và về môi trường khi tỉnh táo và bình thường. Nội dung của ý thức và nhận thức chỉ có thể được kiểm tra mức độ tỉnh táo được duy trì. Chú ý là một chức năng của nhận thức và phụ thuộc vào nhận thức. Nếu ý thức giảm chú ý sẽ giảm. Chỉ đánh giá chú ý ở mức độ ý thức tỉnh táo. Giảm chú ý là một tiêu chí cốt lõi trong tiêu chuẩn chẩn đoán của ICD 10 cụ thể là giảm khả năng tập trung chú ý, duy trì chú ý hoặc thay đổi sự chú ý. Kết quả trong bảng 3.3 cho thấy phân lớn các trường hợp sảng có triệu chứng giảm khả năng duy trì sự chú ý với tỉ lệ $61,3 \%$. Tương đồng với kết quả của chúng tôi, Paula T. Trzepacz (2018) cho biết giảm khả năng tập trung chú ý chiếm tỉ lệ từ 97 đến $100 \%$ và giảm duy trì chú ý chiếm tỉ lẹ $89 \%$. $^{7}$

Đánh giá nhận thức trong sảng cần đánh giá nhiều nội dung nhưng thông thường đánh giá 2 nội dung chính là mất định hướng và suy giảm trí nhớ. Ở sảng do sự suy giảm chú ý sẽ làm giảm khả năng nhận các thông tin mới. Do đó sẽ có sự rối loạn các năng lực định hướng và trí nhớ. Tî lệ rối loạn định hướng trong sảng nằm trong khoảng $43-100 \%$. Theo Sónia Martins và cộng sự (2012) rối loạn định hướng ở bệnh nhân sảng là phổ biến. ${ }^{8}$ Đầu tiển là rối loạn định hướng thời gian sau đó là rối loạn định hướng không gian và rối loạn định hướng bản thân. Đặc biệt các rối loạn này thường xảy ra vào buổi tối và ban đêm và cũng thường nặng lên vào thời điểm này. Tương đồng với nhận định của các tác giả, nghiên cứu của chúng tôi nhận thấy hầu hết các bệnh nhân có rối loạn định hướng về không gian $89,9 \%$ (bảng 3.3).

Suy giảm trí nhớ là một phần của tiêu chuẩn chẩn đoán mê sảng theo ICD 10 . Tỉ lệ suy giảm trí nhớ ở sảng chiếm khoảng $64-100 \%$. Thống kê trên nhiều nghiên cứu Paula T. Trzepacz (2018) cho biết 2 nghiên cứu có tần suất giảm trí nhớ tức thì cao với tỉ lệ lần lượt là $88 \%$ và $92 \%{ }^{7}$ Tương tự như vậy, nghiên cứu của chúng tôi cho biết những bệnh nhân có trí nhớ gần giảm với tỉ lệ $89,6 \%$ (bảng 3.3). Sảng có thể là do sự suy giảm có thể hồi phục của giảm chuyển hóa oxy hóa não và có thể do rối loạn các chất dẫn truyền thần kinh. Sảng thường cấp tính, thoảng qua và có thể hồi phục được. Theo chúng tôi nhận định rối loạn trí nhớ trong sảng thường sẽ là suy giảm trí nhớ tức thì và giảm trí nhớ gần. Nếu sảng lâu ngày và khó phục hồi thì lúc đó sẽ suy giảm trí nhớ xa.

Kết quả nghiên cứu ở bảng 3.3 cũng cho thấy đảo ngược chu kì thức ngủ ít gặp nhất chiếm tỉ lệ $24,5 \%$. Tuy nhiên, phân lớn các tác giả cho biết đảo ngược chu kỳ thức ngủ thường gặp ở người bệnh sảng. Ở những nghiên cứu tiến hành tại khoa hồi sức, tỉ lệ bệnh nhân đảo ngược hoàn toàn chu kỳ thức ngủ hoặc có mức độ rối loạn giấc ngủ nghiêm trơng cao hơn so với các nghiền cứu tiến hành tại các địa điểm khác. Lý do có thể là môi trường nghỉ ngơi tại khoa cấp cứu hoặc hồi sức khá là kích thích đối với bệnh nhân do cường độ ánh sáng cao, liên tục, nhiều tiếng ồn 
hơn và tình trang căng thẳng do nhiều yếu tố xung quanh tác động. Tại khoa cấp cứu bệnh viện Lão khoa Trung ương, nơi chúng tôi tiến hành nghiên cứu có được chia thành nhiều khu vực, nhiều khu phòng nhỏ, được giảm cường độ ánh sáng và hạn chế tiếng ồn vào buổi tối nên bệnh nhân cũng giảm nguy cơ bị rối loạn giấc ngủ nghiêm trong, tỉ lệ đảo ngược hoàn toàn chu kỳ thức ngủ thấp hơn so với các nghiên cứu khác.

\section{KẾT LUÂN}

Người bệnh sảng $\geq 60$ tuổi thường gặp là nhóm tuổi 80 - 89, tuổi trung bình mắc hội chứng sảng là $78,3 \pm 10,9$, nam giới gắp nhiều hơn nữ giới $(52,8$ và 47,2). Phần lớn sống cùng gia đình (68,9\%). Có 2 trường hợp sống trong nhà dưỡng lão chiếm tỉ lệ 1,9\%. Đa số người bệnh có biểu hiện suy giảm thị giác $(87,7 \%)$ và suy giảm thính giác $(81,1 \%)$. Triệu chứng gặp nhiều nhất là biểu hiện rối loạn định hướng không gian và giảm trí nhớ gần với tỉ lệ tương đương nhau là $89,6 \%$. Tiếp đó đến biểu hiện giảm khả năng duy trì sự chú ý $(61,3 \%)$. Ít gặp nhất là biểu hiện đảo ngược chu kì thức ngủ $(24,5 \%)$.

Khuyến nghị. Hội chứng sảng thường gặp ở người $\geq 60$ tuổi. Do đó, bác sĩ đa khoa và các bác sĩ chuyên khoa cần lưu ý để tránh bỏ sót.

Lời cảm ơn. Tôi xin chân thành cảm ơn những người bệnh và gia đình tham gia vào nghiên cứu, cảm ơn Khoa Cấp cứu bệnh viện Lão khoa Trung ương đã tạo điều kiện cho việc thực hiện nghiên cứu.

\section{TÀI LIÊU THAM KHẢO}

1. Kennedy M, Hwang $U$, Han JH. Delirium in the Emergency Department: Moving from tool-based research to system-wide change. J Am Geriatr Soc. 2020;68(5):956-958. doi:10.1111/jgs.16437

2. Wass S, Webster PJ, Nair BR. Delirium in the Elderly: A Review. Oman Med J. 2008;23(3):150-157.

3. Fong TG, Tulebaev SR, Inouye SK. Delirium in elderly adults: diagnosis, prevention and treatment. Nat Rev Neurol. 2009;5(4):210-220. doi:10.1038/nrneurol.2009.24

4. Carpenter CR, Bassett ER, Fischer GM, Shirshekan J, Galvin JE, Morris JC. Four sensitive screening tools to detect cognitive dysfunction in geriatric emergency department patients: brief Alzheimer's Screen, Short Blessed Test, Ottawa 3DY, and the caregiver-completed AD8. Acad Emerg Med Off J Soc Acad Emerg Med. 2011;18(4):374-384. 2712.2011.01040.x

5. Han JH, Vasilevskis EE, Chandrasekhar R, et al. Delirium in the Emergency Department and Its Extension into Hospitalization (DELINEATE) Study: Effect on 6-month Function and Cognition. J Am Geriatr Soc. 2017;65(6):1333-1338. doi:10.1111/jgs.14824

6. Pisani MA, Murphy TE, Van Ness PH, Araujo KLB, Inouye SK. Characteristics associated with delirium in older patients in a medical intensive care unit. Arch Intern Med. 2007:167(15):16291634. doi:10.1001/archinte.167.15.1629

7. Trzepacz PT, Franco JG, Meagher DJ, et al. Delirium Phenotype by Age and Sex in a Pooled Data Set of Adult Patients. J Neuropsychiatry Clin Neurosci. 2018;30(4):294-301. doi:10.1176/appi.neuropsych.18020024

8. Martins $\mathbf{S}$, Fernandes $\mathbf{L}$. Delirium in elderly people: a review. Front Neurol. 2012;3:101. doi:10.3389/fneur.2012.00101

\section{NGHIÊN CỨU TỔNG QUAN HÊ THỐNG VỀ ĐÁNH GIÁ KĨ NĂNG THỰC HÀNH NGHỀ NGHIỆP CỦA NHÂN VIÊN BÁN HÀNG TẠI CÁC NHÀ THUỐC TƯ NHÂN}

\section{TÓM TẮT}

Dược sĩ cộng đồng (DSCĐ) là nhân tố quan trong trong vân hành hệ thống y tế đảm bảo sức khỏe cộng đồng nển cần đảm bảo kiến thức chuyên môn và trau dồi kỹ năng thực hành nghề nghiêp (KNTHNN). Tổng quan hệ thống các kết quả đánh giá kỹ năng thực

*Đai hoc Y Dươ TP.HCM

Chịu trách nhiệm chính: Nguyễn Thị Thu Thủy

Email: nguyenthuthuy@ump.edu.vn

Ngày nhận bài: 15.9.2021

Ngày phản biên khoa hoc: 12.11.2021

Ngày duyệt bài: 22.11.2021

\section{Võ Thảo Nguyên*, Nguyễn Thị Thu Thủy*}

hành nghề nhiệp của nhân viên bán hàng tại các nhà thuốc tư nhân trên thế giới là cần thiết nhằm cung cấp bức tranh toàn cảnh về đặc điểm, kỹ năng hành nghề cũng như các yếu tố liên quan đến KNTHNN của dược sĩ cộng đồng. Phân tích tổng quan hệ thống được thực hiện theo tiêu chuẩn PRISMA trên cơ sở dữ liểu Pubmed, Cochrane và Research Gate bằng câu lệnh, từ khóa và tiêu chí lựa chọn, loại trừ phù hợp. Dữ liệu về đăc điểm các nghiên cứu và đánh giá KNTHNN của DSCĐ được trích xuất và tổng hợp. Trong 6 nghiên cứu được chon, có 4 nghiên cứu sử dung phương pháp mồ phỏng đóng vai người mua, 2 nghiên cứu khảo sát tư đánh giá và quan sát bí mât. Kỹ năng hỏi thu thập thông tin từ người bệnh có tỉ lệ chênh lệch 